Canadian Journal of Family and Youth, 14(1), 2022, pp. 255-259

ISSN 1718-9748@ University of Alberta

http://ejournals,library,ualberta.ca/index/php/cjfy

\title{
Barkin, Janna. (2017). He's Always Been My Son: A Mother's Story About Raising Her Transgender Son. Philadelphia: Jessica Kingsley Publishers.
}

\author{
Reviewed by: Riley Cadieux, MacEwan University
}

In the book, "He's Always Been My Son: A Mother's Story About Raising Her Transgender Son" written by Janna Barkin, Barkin's purpose is to bring awareness and acceptance to the transgender community, as well as to inspire others. Barkin accomplishes this by discussing the journey of her own transgender son Amaya, as he developed and transitioned from a female to a male. Throughout the book, Barkin discusses the transition of Amaya and the numerous difficulties he faced through the various stages, which is common to most transgender people: the before years, the early years, the tween years, the transition years, and the complete. Barkin combines various perspectives together to tell the story of the development of her child Amaya. These perspectives included but were not limited to her perspective as the mother, her husband, Amaya, her siblings, and many other family and friends. Each chapter of the book explains Amaya's transition throughout the stages in his life that are mentioned above.

Barkin brings awareness to the readers that most transgender people have a very short period of time in their lives in which they feel congruent with their assigned gender. She discusses how there is a misconception out there in which people think that transgenderism is a choice among people, sometimes a cry for attention, but Barkin says that is not the case at all. In taking the audience through Amaya's story, Barkin shows the audience how transgender people often know 
from an early age that they do not necessarily fit their gender that was assigned to them at birth. In Amaya's case, Barkin believes that Amaya knew from around the age of three that she was not exactly congruent with her label as a female. Barkin explains that Amaya, along with many other transgenders have always felt, for most of their lives that their inner sense of self was that their gender was different from what the rest of the world perceived them to be. Very early on, Amaya refused to wear dresses and things that stereotypically a girl would wear, and Barkin believed that this was just one of the many ways in which her child was trying to express himself to her. Barkin goes on to explain that the period of transition for transgenders and non conforming people is often times a slow, and gradual approach. Although the child may know early on that they feel different, it is likely difficult to express due to the fact that they do not exactly know much about gender identity yet, and do not have the means to express themselves completely at the time.

In Barkin's experience with her son's transition, in hindsight there were many signs pointing towards Amaya being incongruent with his assigned gender as a female, further proving that there is a misconception that becoming a transgender is a choice that comes later in life. Barkin wanted to bring awareness that parents of children should be on the lookout for potentially early signs of a child trying to express their gender identity, and to focus on "...behaviour that is consistent, persistent, and insistent." Reflecting back on the younger years of Amaya as a child, Barkin believed Amaya was trying to express his gender identity in numerous instances. One early instance included Amaya always dressing like his older brother Travis, instead of his other sibling Emily. Although Amaya had female on his birth certificate, Amaya never enjoyed wearing dresses and stereotypical fashion that was associated with females. Barkin mentions a situation in which 
Amaya was asked to be a flower girl, but seemed very unpleasant with having to put on a dress, even at the age of three. Later on in Amaya's life, when it was time to go shopping for clothing items like bras, Amaya would lash out into panic attacks, and would not look forward to these shopping trips at all, as he preferred wearing loose clothing that was more associated with a stereotypical boy. Even reflecting back on it, Barkin recalls that every time she saw Amaya in clothing associated with girls, that for some reason the clothes just did not look right on Amaya, yet another potential sign that Amaya would not grow up to identify as a female.

Barkin also recalls the moment of Amaya's birth. She explains that as a mother, she did not wish to know the gender of her baby ahead of time, and that the family agreed to give the older daughter Emily the task of telling Amaya's gender to the family, upon delivery. When Amaya was delivered, although the baby clearly had a vagina and the sex was a girl, Emily blurted out that she thinks the baby is a boy. Barkin, in hindsight believes that this was just one of many signs, that her child Amaya would not identify with the assigned sex at birth.

In addition to bringing awareness to transgenderism, Barkin also attempts to make the readers empathize with transgender people to become more accepting. Barkin describes the various difficulties that Amaya had to go through in his process of transitioning, in hopes that upon learning of the struggles and courage it takes to transition, people will become more understanding. Barkin describes how physically and emotionally draining it was for Amaya, to not be able to fully express himself as a transgender person for so long, likely due to him not knowing if others would accept him or not. Not fully understanding his gender identity, and not knowing how to express it took a toll on Amaya, and damaged his emotional state, often leaving him exhausted and depressed. 
Barkin explains that people and in particular parents impose heavy expectations on their children in what they will become and that "from the moment they are born and even way before a child is conceived, we develop an image of who our child will be." Although, it can be difficult, Barkin believes that all people, through educating themselves on transgenderism can get past these heavy expectations that they impose, and become a system of support for transgender children, instead of a burden.

Barkin's intended audience in this book is for mainly children who are struggling with their gender identity, and for parents who are unsure how to help their gender non-conforming child. I believe the book is also great for anyone who does not fully understand the concept of transgenderism, and can a great educational tool for teachers, doctors, and many others.

Overall, Barkin accomplishes what she aims to in this book. Barkin is seemingly able to bring us along in the journey that she and her child Amaya had to go through on Amaya's way to transitioning from a female to a male. I believe the book can be a great educational tool for people of all ages, as it can bring awareness and more acceptance towards the LGBTQ+ community, particularly the transgender community. “He’s Always Been My Son: A Mother's Story About Raising Her Transgender Son" takes the reader through a rollercoaster of emotions but is a very heartwarming and enjoyable read. The only aspect I might suggest changing for improvement is that at times I felt that the book could be repetitive in some instances, and that some details were discussed for longer than they needed to be. Other than that, I highly recommend this book to people of all ages, but specifically to gender non-conforming children, and their parents. I also 
believe that the book could be used for educational purposes by psychologists, and sociologists, so that research could be done for assessment on transgender youth and their relationships. The book can be very informative and sheds some light into a community that is often misunderstood by many. 